Article

\title{
Effective Experiences: A Social Cognitive Analysis of Young Students' Technology Self-Efficacy and STEM Attitudes
}

\author{
Kuo-Ting Huang ${ }^{1, *}$, Christopher Ball ${ }^{2}$, Shelia R. Cotten ${ }^{3}$ and LaToya $\mathrm{O}^{\prime}$ Neal $^{4}$ \\ ${ }^{1}$ Department of Journalism, Ball State University, Muncie, IN 47306, USA; E-Mail: khuang2@bsu.edu \\ 2 Department of Journalism, University of Illinois at Urbana-Champaign, Urbana, IL 61820, USA; E-Mail: drball@illinois.edu \\ 3 Department of Media \& Information, Michigan State University, East Lansing, MI 48824, USA; E-Mail: cotten@msu.edu \\ ${ }^{4}$ Department of Family, Youth and Community Sciences, University of Florida, Gainesville, FL 32611, USA; \\ E-Mail: latoya.oneal@ufl.edu \\ * Corresponding author
}

Submitted: 1 November 2019 | Accepted: 3 March 2020 | Published: 14 May 2020

\begin{abstract}
The development of computer skills, as well as computer self-efficacy, has increased in importance along with the role of technology in everyday life. Childhood is a critical time for the development of these skills since early inequalities may substantially impact future life outcomes. In a context of a computing intervention designed to improve digital inclusion, we hypothesize that students' enactive learning experience (conceptualized as their computer usage) and their vicarious learning experience (conceptualized as their perception of their teacher's computer usage) are associated with the development of perceived technology efficacy and STEM (Science, Technology, Education, and Math) attitudes. Data are from a sample of elementary school students from an urban school district in the Southeastern United States. The results show that both their direct experiences and their perception of their teacher's computer usage have strong impacts on students' technology efficacy and STEM attitudes, and the former is the stronger predictor of the outcomes examined. The findings suggest that programs aiming to improve digital inclusion should emphasize students' direct learning experience, which would later improve their attitude toward STEM fields.
\end{abstract}

\section{Keywords}

digital inclusion; enactive experience; learning; perception of teachers; STEM attitudes; students; technology efficacy; vicarious experience

\section{Issue}

This article is part of the issue "Digital Inclusion Across the Globe: What Is Being Done to Tackle Digital Inequities?" edited by Bianca C. Reisdorf (University of North Carolina at Charlotte, USA) and Colin Rhinesmith (Simmons University, USA).

(C) 2020 by the authors; licensee Cogitatio (Lisbon, Portugal). This article is licensed under a Creative Commons Attribution 4.0 International License (CC BY).

\section{Introduction}

The demands placed upon "digital natives" (Prensky, 2001) will continue to evolve as our society shifts from an advanced industrial-based economy towards an information-based economy. The children of today will move into a workplace and become part of a workforce that is very different from their grandparents. The digital generation of children will need a host of computer, information processing, and critical thinking skills in order to be successful in this information age. Unfortunately, some children are not receiving these increasingly important digital skills and abilities even when they have access to computers and the Internet.

Previous research has focused on a multitude of digital inequalities involving those that have access and experience with information and communication technologies (ICTs) and those who do not (Araque et al., 2013; DiMaggio, Hargittai, Celeste, \& Shafer, 2004; Robinson et al., 2015). The differential impact of the digital divide remains (Hassani, 2006; Vandoninck \& Roe, 2008) despite progress to close the gap for certain groups (e.g., 
women; van Dijk \& Hacker, 2003). Specifically, access to ICTs (i.e., digital divide) is important because it can lead to other disparities in users' ICT related knowledge, skills, and willingness to use ICTs (i.e., digital inequality). Consequently, the impact of digital inequality and the need for digital inclusion cannot be understated as the world becomes increasingly digitalized. Digital inclusion is necessary because unequal access to information impacts children's ability to succeed in school and, in turn, their access to quality higher education which subsequently determines the returns on their financial investment of education (DiMaggio et al., 2004). Furthermore, a lack of digital inclusion can negatively affect students' job search self-efficacy (Fieseler, Meckel, \& Muller, 2014) and college prospects, which may lead to investment in a lower quality college degree with reduced financial returns (Melguizo \& Wolniak, 2012). Further still, information access disparities may have broader healthrelated impacts on children and adults by limiting their access to digital health services (Robinson et al., 2015). Therefore, we must seek new means and methods to increase disadvantaged children's digital inclusion because a lack of ICT skills and experiences can have far-reaching consequences for children's lives and potentially for society as a whole (DiMaggio et al., 2004; Ritzhaupt \& Hohlfeld, 2018).

Digital inclusion has also been linked to a broader range of outcomes connected to life trajectories (Robinson et al., 2015). Recent national initiatives seek to increase minority presence in Science, Technology, Education, and Math (STEM) careers and fields for two reasons (National Science Foundation, 2011). First, increasing minority presence in STEM is needed in order to alleviate economic inequality, as racial/ethnic minorities in STEM careers earn between 26 to nearly $40 \%$ more income compared to those who are in social science fields (Melguizo \& Wolniak, 2012). Furthermore, Increasing ICT experiences may strengthen minority students' interest in potentially lucrative STEM-based careers. Tapping into the "hidden workforce" of minorities increases the potential standing of minority students as well as our nation as a whole (Frehill, Di Fabio, \& Hill, 2008). Therefore, we examine the potential influence of digital inclusion on minority students' interest in STEM fields.

This study adds to our understanding of digital inclusion by investigating several factors that potentially improve digital inclusion and subsequently bolster minority students' interest in STEM careers. Social cognitive theory provides the theoretical framework of this study by contributing to the conceptual cornerstone of self-efficacy (Bandura, 1994). In short, self-efficacy is an individual's belief in their ability to perform a task and achieve a desired outcome. Social cognitive theory posits that enactive experiences and vicarious experiences influence self-efficacy. When a person performs a task the enactive experience either increases or decreases selfefficacy through success or failure. Vicarious experience is the observation of another person performing a task.
We examined if students' ICT usage (enactive experiences) and students' perceptions of their teachers' ICT usage (vicarious experiences) improve digital inclusion by impacting young, predominantly minority, urban students' technology self-efficacy and STEM attitudes.

We begin with a traditional literature review (i.e., narrative review) of some the relevant studies surrounding the digital divide as an evolving and persistent social problem. Next, we provide an in-depth overview of the key concepts within social cognitive theory. The analysis employs data from a large-scale elementary school computing intervention in the Southeastern United States. We conclude with a discussion of the implications of the presented research and some potential directions for future research.

\section{Literature Review}

\subsection{Digital Inequality: Hardware to Self-Efficacy}

Recent discussions of digital inclusion and inequality have shifted from a focus on hardware access to a more nuanced and multidimensional perspective (van Deursen \& van Dijk, 2013). Perhaps most prominently, van Dijk and Hacker (2003) propose that there is not a singular access gap but rather four distinct access gaps. The first is a mental access gap which also referred as motivational access gap in van Dijk's later work (van Dijk, 2005). The mental/motivational access gap is an emotional gap relating to people's unwillingness to use ICTs and their lack of interest ICTs, stemming from a lack of elementary experience with ICTs. The second gap is a material access gap, which posits that people simply do not have access to computers or the Internet. The third gap, skills access gap, focuses on how people with differing levels of ICT experience develop different skill levels. The final gap is a usage access gap, which posits that people with different ICT experiences will develop different usage patterns and habits.

These diverse access gaps and discrete levels of the digital divide now receive increased attention. Van Dijk and Hacker (2003) point out that mental access may lead to a kind of "computer anxiety" which turns "information have-nots" into "information want-nots." Similar to the concept of mental access, further studies have found that due to temporal barriers (such as having to share a family computer) and physical barriers (such as having to find transportation to a library) many of today's youth have to deal with what are termed emotional costs (Robinson, 2009). Emotional costs are feelings of anxiety or stress that can be associated with using computers. Also, long-term material deprivation causes students to experience negative emotions such as low self-efficacy or high anxiety when they use ICT (Robinson, 2014). In the context of a computing intervention, Huang, Robinson, and Cotten (2015) found that students' emotional costs, as an extension of mental access, had a negative impact on students' self-perceived technology efficacy. In sum, 
mental access and self-efficacy have become more important issues when discussing digital inclusion and the different forms of digital inequalities. In the following section, we review the literature on factors that influence the formation of self-efficacy.

\subsection{Factors Forming Self-Efficacy in the Classroom: Enactive and Vicarious Experiences}

Previous research has shown that self-efficacy plays an important role in students' learning in the classroom setting, such as physics (Kapucu \& Bahçivan, 2015), chemistry (Boz, Yerdelen-Damar, Aydemir, \& Aydemir, 2016), and mathematics (Ng, Lay, Areepattamannil, Treagust, \& Chandrasegaran, 2012). One study found that high school students' self-efficacy had an effect on their chemistry achievement and also mediated the relationship between students' perceptions of their learning environment and their chemistry achievement (Boz et al., 2016). In other words, self-efficacy can not only affect students' achievement but also influence the effects of their learning environment on achievement. Therefore, we need to understand how self-efficacy is formed in the classroom.

Regarding the formation of self-efficacy, Bandura (1977, 1994, 2004) expanded upon traditional environmental and impulse-based learning theories to posit a conception of humans as proactive and self-reflecting. The three intellectual cornerstones of modern social cognitive theory form the theoretical foundation for the present study: self-efficacy, enactive experience, and vicarious experience. Self-efficacy refers to people's beliefs about their ability to perform an action, such as completing a task or reaching a goal. Moreover, self-efficacy influences how people think, feel, and motivate themselves to behave (Bandura, 1994). Thus, self-efficacy becomes a powerful indicator to predict motivation and accomplishment. The underlying logic follows that if an individual does not believe that they possess the skills or ability to perform a task, then they will be less likely to even attempt to perform said task. Conversely, if they have a strong belief in their ability to carry out a particular task, then their likelihood of attempting that task increases substantially (Peng, 2008). Self-efficacy is also related to many other cognitive processes, such as the ability to recover from failure and persist in the face of challenges. Therefore, self-efficacy is an essential element for overcoming the multitude of situations that present themselves across the many stages of life.

Bandura $(1994,2004)$ posits that there are four ways to influence self-efficacy; however, we focus on two of the most important for this study. The first and most effective is enactive experiences (Bandura, 2004). Enactive experiences are experiences in which individuals develop beliefs about their ability to perform an action by interpreting the results of their actual behaviors (Pajares, Prestin, Chen, \& Nabi, 2009). Individuals have a direct experience in which they actually carry out a set of actions. In essence, individuals interpret outcome feedback in order to develop their knowledge and skills through practice (Wei, Teo, Chan, \& Tan, 2014). Enactive experience can have a substantial impact on an individual's self-efficacy because success will boost efficacy beliefs while failure will detract from it. Empirical studies reveal that enactive experience can be a source of support and self-efficacy when middle school students are learning mathematics (Usher, 2009) and science (Kiran \& Sungur, 2012). Research on technology-focused efficacy also indicates that students' technology ownership, total amount of technology use, and specific media usages (e.g., email use) had a positive association with technology self-efficacy (Shank \& Cotten, 2014). Therefore, we hypothesize that students' enactive experiences, which we operationalized as their direct experience of computer usage, will have higher self-perceived technology efficacy and STEM attitudes (H1).

Vicarious experiences are the second means to influence self-efficacy. In this case, an individual observes a social model perform certain actions (Pajares et al., 2009; Peng, 2008). As a source of self-efficacy, vicarious experiences transmit knowledge and skills to observers about effective actions (Wei et al., 2014). The success or failure of the social model then affects the self-efficacy beliefs of the observer. Thus, observing the success of others boosts the beliefs that an individual possesses regarding their ability to also perform the observed task. Likewise, observing failure can undermine an individual's belief in their ability to succeed. The vicarious relationship strengthens depending on the perceived "closeness" or similarity of the social model with the observer (Bandura, 1994; Benight \& Bandura, 2004). For instance, the vicarious impact of a student observing another student/peer, that is also perceived to be close in ability, will have a greater impact than observing a teacher. Vicarious experiences provide an action template to the observer as they see what actions lead to successful outcomes.

Vicarious social models can come in many forms and can even be mediated through television (Bandura, 2004) and video games (Peng, 2009). Previous research examining the influence of social learning environments on students' science and math self-efficacy found that peer-based vicarious experiences are indeed a source of self-efficacy (Joet, Usher, \& Bressoux, 2011; Kiran \& Sungur, 2012; Usher, 2009). Furthermore, other studies reveal that students vicariously acquire science efficacy (Kiran \& Sungur, 2012) or ICT self-efficacy (Aesaert \& van Braak, 2014) from the adults around them. Research on technology-focused interventions also suggests that teachers' computer efficacy plays an important role in technology education (Paraskeva, Bouta, \& Papagianni, 2008) and may have direct impacts on student's digital literacy (Zhu, Yang, MacLeod, Yu, \& Wu, 2019). Therefore, we hypothesize that students' vicarious experience, which is operationalized as students' perception of their teacher's computer usage, will positively influence students' technology self-efficacy and STEM attitudes in the context of a computing intervention $(\mathrm{H} 2)$. 
Although both enactive and vicarious experiences are sources of self-efficacy, enactive experiences are more powerful when forming self-efficacy beliefs (Peng, 2008). Previous research examining students' math selfefficacy found that enactive experience is a stronger predictor than vicarious experience (Joet et al., 2011). Therefore, we hypothesize that enactive experiences, compared to vicarious experiences, will have stronger predictive power regarding students' technology efficacy and STEM attitudes (H3).

\section{Methods}

\subsection{Data Collection}

The data for this study was collected from a computing intervention that involved 12 public schools in a large, high poverty, minority, urban school district in the Southeastern United States. The demographic composition of the school district, $88 \%$ of students receiving free or reduced-price lunches (which is a proxy for poverty levels) and 95\% African Americans, made it an ideal setting for an intervention focused on increasing the number of minority students interested in STEM fields and careers. Fourth and fifth grade teachers and students participated in a number of computer-based activities throughout the intervention. Specifically, teachers participated in numerous computer-based trainings during the year where they learned to integrate computing across their curriculum. Trainings focused on blogging, computer programming, creating tables and graphs, and various other activities to promote student interest in STEM.

Students enrolled in these schools were asked to complete surveys at the beginning (Fall 2012) and the end (Spring 2013) of the school year. A total of 123 teachers participated in the intervention, while 73 teachers were involved in an intensive summer workshop. Students voluntarily participated and received an incentive regardless of their completion of the surveys. Over 95\% of the students participated in either the pretest or posttest survey. A total of 1,201 students participated in both surveys. Observations with missing data on the predictors of interest were excluded from the analysis, which reduced the sample from 1,201 to 976 students. There were no significant differences in the results after excluding observations with missing data.

\subsection{Dependent Variables}

The surveys included a series of items which measured students' computer usage and attitudes toward computers and STEM fields during a computing intervention. The dependent variables included in this study are: (1) selfperceived technology efficacy and (2) STEM attitudes. The self-perceived technology efficacy scale included five questions asking students to rate their skill level while using the following ICTs (e.g., computer or laptop and Internet). The response option values for each dimension
( 0 = not at all, $1=$ only a little, $2=$ some, $3=$ a lot $)$ were summed and averaged. The STEM attitudes scale items included nine questions asking students whether they agreed or disagreed with statements such as: I think science is cool and I think math is cool. Both scales have been validated in previous research on STEM education (e.g., Ball, Huang, Cotten, \& Rikard, 2017; Huang et al., 2015). Negatively phrased questions were reverse coded and the response option values for each dimension ( $0=$ disagree, $1=$ not sure, $2=$ agree) were summed and averaged. To control the effects of dependent variables in the pretest on the same variables in the posttest, both pretest and posttest variables were included in the data analyses.

\subsection{Independent Variables}

The independent variables of interest included: (1) enactive experience, which refers to students' computer usage and (2) vicarious experience, which refers to students' perception of their teacher's computer usage in class. The enactive experience scale consisted of 11 items asking students to report how often they use computers to do things such as homework and research. The vicarious experience scale consisted of nine items asking students to report how much their teacher used various software in class such as Microsoft Word, Microsoft Excel, and Microsoft PowerPoint. The response option values for each dimension ( $0=$ not at all, $1=$ only a little, 2 = some, $3=$ a lot) were summed and averaged.

\subsection{Control Variables}

Sex, race, and grade served as the control variables in the analyses. Sex $(0=$ female, $1=$ male $)$ and race ( 0 = African American, $1=$ non-African American) were recoded as dichotomous dummy variables, with female and African American respondents being the excluded category. Students' grade was also recoded as a dichotomous dummy variable ( $0=$ fourth grade, $1=$ fifth grade) and fourth grade students were the excluded category. This study did not include a measure of socioeconomic status in the analyses due to a lack of variation in students' socioeconomic backgrounds.

\subsection{Data Analysis}

First, we report the descriptive statistics for the variables of interest. Second, the variables were used in a series of Ordinary Least Squares (OLS) regression models. Hierarchical Linear Modeling was also considered, but none of the intraclass correlation coefficients for the relationship between-school and between-class clusters and the dependent variables were large enough for us to use it. The OLS regression models investigated the relationship between the predictors (i.e., enactive and vicarious experiences) and our outcome variables (self-perceived technology efficacy and STEM attitudes). Three models 
pertaining to each dependent variable were created for this research. The first model included our dependent variables measured in the pretest while controlling for sex, race, and grade. Given that the outcome variables in the pretest may have a strong impact on the same outcome variables in the posttest, we controlled for the effects of the outcome variables in the pretest by adding students' self-perceived technology efficacy or STEM attitudes into the first model. Next, we tested for a relationship between the posttest vicarious experience and the posttest outcome variables in the second model. Lastly, the posttest direct experience was added into the regression model to see if vicarious experience was weakened by the inclusion of direct experience.

\section{Results}

\subsection{Descriptive Statistics}

Table 1 presents the descriptive statistics for the variables of interest. Approximately half (50.2\%) of the participants were male, and $54 \%$ of the participants were in the fifth grade. Students had some enactive experience $(\bar{X}=1.60)$ but low scores on vicarious experience $(\bar{X}=0.89)$ on average. The majority of the students had relatively strong inclinations toward STEM fields at the pretest $(\bar{X}=2.46)$ and posttest $(\bar{X}=2.41)$, and the strength of their STEM attitudes at pretest and posttest showed no significant difference. For their technology efficacy score, participants had an average score of 3.21 on the pretest and 3.47 on the posttest.

\subsection{Regression Analyses}

\subsubsection{Self-Perceived Technology Efficacy}

Table 2 presents the three OLS regression models. Sex, race, grade, and self-perceived technology efficacy at the pretest were entered into Model 1 (see Table 2). Students' self-perceived technology efficacy $(\beta=0.397$, $\mathrm{p}<0.001)$ and grade $(\beta=0.069, \mathrm{p}<0.01)$ had a significant impact on students' technology self-efficacy in the posttest. The second model added the measure of students' vicarious experience. The results showed that students' vicarious experience $(\beta=0.091, \mathrm{p}<0.01)$ significantly predicted students' technology efficacy after the computing intervention. Students who had higher scores on vicarious experience were expected to have higher scores on self-perceived technology efficacy.

However, after adding students' enactive experience in the third model, the coefficient of vicarious experience decreased by $82.4 \%$ and was no longer significant. Students' enactive experience predicted their selfperceived technology efficacy in the posttest survey ( $\beta=0.272, p<0.001)$. The effect of vicarious experience on students' self-perceived technology efficacy was

Table 1. Descriptive statistics of variables.

\begin{tabular}{lccrr}
\hline Variable & Mean & Std Dev & Min & Max \\
\hline Sex (1 = male) & 0.50 & 0.50 & 0.00 & 1.00 \\
Race (1 = non-African American) & 0.18 & 0.38 & 0.00 & 1.00 \\
Grade (1 = fifth grade) & 0.54 & 0.50 & 0.00 & 1.00 \\
Self-perceived technology efficacy (Time1) & 3.21 & 0.83 & 0.00 & 4.00 \\
Self-perceived technology efficacy (Time2) & 3.47 & 0.64 & 0.00 & 4.00 \\
STEM attitudes (Time 1) & 2.46 & 0.34 & 1.00 & 3.00 \\
STEM attitudes (Time 2) & 2.41 & 0.34 & 1.00 & 3.00 \\
Enactive experience & 1.60 & 0.51 & 0.00 & 3.00 \\
Vicarious experience & 0.89 & 0.61 & 0.00 & 3.00 \\
\hline
\end{tabular}

Note: $\mathrm{N}=976$.

Table 2. OLS regression analysis of student's self-perceived technology efficacy and STEM attitudes regressed on enactive and vicarious experience.

\begin{tabular}{|c|c|c|c|c|c|c|}
\hline \multirow[t]{2}{*}{ Variable } & \multicolumn{3}{|c|}{ Self-perceived technology efficacy } & \multicolumn{3}{|c|}{ STEM attitudes } \\
\hline & Model 1 & Model 2 & Model 3 & Model 1 & Model 2 & Model 3 \\
\hline Sex & 0.025 & 0.027 & 0.035 & $0.126 * * *$ & $0.129 * * *$ & $0.135 * * *$ \\
\hline Race & -0.028 & -0.024 & -0.030 & 0.010 & 0.018 & 0.017 \\
\hline Class grade & $0.069 * *$ & $0.066^{* *}$ & 0.055 & $-0.089 * *$ & $-0.095 * *$ & $-0.104 * *$ \\
\hline DV in the pretest & $0.397 * * *$ & $0.394 * * *$ & $0.325 * * *$ & $0.318^{* * *}$ & $0.302 * * *$ & $0.288^{* * *}$ \\
\hline Vicarious experience & & $0.091^{* *}$ & 0.016 & & $0.155^{* *}$ & $0.110 * * *$ \\
\hline Enactive experience & & & $0.272 * * *$ & & & $0.160 * * *$ \\
\hline $\mathrm{F}$ & $48.579 * * *$ & $41.157^{* * *}$ & $50.376 * * *$ & $38.235 * * *$ & $36.865^{* * *}$ & $36.151 * * *$ \\
\hline $\operatorname{Adj}-R^{2}$ & 0.163 & 0.171 & 0.233 & 0.133 & 0.155 & 0.178 \\
\hline
\end{tabular}

Notes: $\mathrm{N}=976 ;{ }^{*} \mathrm{p}<0.05 .{ }^{* *} \mathrm{p}<0.01 .{ }^{* * *} \mathrm{p}<0.001$. Sex: 1 = male; Race: 1 = non-African American; Class Grade: $1=$ fifth grader. 
weaker than their enactive experience of actually using a computer.

\section{Discussion}

The impact of digital inequalities and the subsequent need for digital inclusion has been examined across a broad range of life chances and life trajectories (Robinson et al., 2015). The present study investigated how different types of experiences link to inequalities and influence students' self-perceived technology efficacy and STEM attitudes in the context of a large-scale computing intervention. The results show that students who had more enactive experiences related to their direct usage of computers had higher technology-related selfefficacy and STEM attitudes compared to students that had fewer enactive experiences. The findings support the first hypothesis and articulate the importance of usage access to increase digital inclusion. Also, the results indicate that students' vicarious experiences related to observing their teachers' technology use had a positive influence on their technology efficacy. However, the effects of students' vicarious experiences on students' selfperceived technology efficacy were mediated by enactive experiences. In other words, the second hypothesis of this research was partially supported. When comparing enactive and vicarious experiences, the regression results show that enactive experiences had stronger effects than vicarious experiences on students' self-perceived technology efficacy and STEM attitudes, which supports the third hypothesis.

Overall, by building our research based on Bandura's (2004) social cognitive theory, we examined factors influencing the formation of self-efficacy in both enactive and vicarious experiences and found that enactive experience indirectly influenced the predictive power of vicarious experience on students' self-perceived technology efficacy. To be more specific, the influence of students' vicarious experience on their technology efficacy was actually based on their computer usage. When controlling for the effects of enactive experience, vicarious experience was no longer a predictor. Rather, students' enactive experience, which was positively related to their vicarious experience, was the main source of students' technology efficacy. The findings articulate the importance of both enactive and vicarious experiences related to the direct effects of using computers and the indirect effects of observing a model to increase digital inclusion with young, urban, minority students. In sum, we found that high technology self-efficacy was associated with computer experience, both directly (direct experience) and indirectly (vicarious experience).

Our results connect research on access and usage inequality to research on affective factors of using technology by illustrating how increased computer usage and observational experience can help digitally disadvantaged students receive tangible outcomes (i.e., interest in STEM fields). The conception of digital inequal- ity encompasses more than a simple lack of ICT access. Digital Inequality followed by limited access includes a lack of self-confidence and inclination toward STEM fields, which later acerbates existing offline inequalities (van Deursen, 2015). Hence, when students experience limited opportunities for enactive and vicarious learning then a subsequent lack of technology self-efficacy will perpetuate already present hindrances. Lower technology self-efficacy in conjunction with other digital inequality factors could affect certain computer usage patterns in the future. Therefore, to increase digital inclusion we must provide opportunities for students improve their self-efficacy with ICTs via direct experiences.

Regarding the effects of vicarious experience, we found that observing teachers provided students with increased opportunities to develop STEM attitudes after controlling for the effects of enactive experience. That is, once students gain the experience of watching their teachers use various computer programs, often they may develop more positive attitudes toward STEM-related fields. Finally, we found that students' enactive experiences did, indeed, have a greater impact on their technology efficacy when compared to the impact of observing their teacher's computer usage. These findings help us to better understand the mechanisms associated with the formation of technology self-efficacy which can help improve digital inclusion in the context of a computing intervention. As previous studies have shown, the digital divide is an increasingly multi-dimensional issue that has expanded beyond simple ICT access. Our study demonstrates the importance of experiences, in addition to access, to increase digital inclusion via technology selfefficacy for digitally disadvantaged students. In summation, the enactive experience of computer usage helps students form their technology-related self-efficacy directly and also indirectly influences their technology efficacy via the routes of vicarious experience.

\section{Limitations}

In light of these findings, we acknowledge that there were some limitations inherent in the present research. First, the computing intervention took place in a high poverty urban school district in the Southeastern United States. These results provided evidence that the intervention was successful at increasing the technology efficacy of students in low socioeconomic status areas. However, these results may be less applicable to students from other socioeconomic backgrounds.

Second, our sample was primarily African American (82\%). Therefore, these findings may not be completely generalizable to students from other racial/ethnic groups. In other words, we are unable to determine if enactive and vicarious experiences impact all racial/ethnic students the same way or if the effects found here only apply to African American students from low socioeconomic status, high poverty school districts in the Southeast. 
Third, due to the limited answer variety, the reliability of some of the measures was relatively low. However, it is normal to have relatively low reliability when analyzing survey data from very young respondents (Newman \& McNeil, 1998). Finally, some potentially important measures were not included in this study. First, we did not include any measures of the actual hours of computer use for students. Second, we did not include any measures of how good teachers were at using the different applications. Third, we did not have any measures related to students vicariously observing peers. Future studies should consider including these measures for a better understanding of the effects of enactive and vicarious experiences.

\section{Conclusion}

Given these limitations, our research still offers several contributions to the literature surrounding the relationship between digital inclusion, digital inequality, and other forms of inequality. First, our research found that students' enactive experience, which refers to their computer usage, was an important factor for increasing children's technology efficacy and STEM attitudes in the context of a computing intervention. Specifically, we found that simply providing students access to digital devices would not be enough to increase their technology efficacy or trigger their STEM attitudes. Instead, we found that increasing their actual computer usage was the key factor for increasing technology efficacy and STEM attitudes. Therefore, future computing interventions seeking to improve digital inclusion should focus their attention on increasing students' actual computer usage through enactive experiences.

Second, our research revealed the impact of vicarious learning experiences on students' STEM attitudes. When students perceived their teachers using computer programs more often, they had higher STEM attitudes. This finding also showed the importance of teachers' roles in promoting STEM education. To improve digital inclusion, computing interventions should tailor pedagogical approaches that bolster computer usage (enactive experiences) and teachers' technology usage in the classroom, which students subsequently observe and internalize (vicarious experiences), especially among digitally disadvantaged students. In the end, these findings indicate that there is a potential opportunity for school districts to trigger minority students' interest in STEM fields via digital inclusion by creating positive opportunities for both enactive and vicarious learning experiences.

Third, previous research has posited that affective experiences may account for some of the negative attitudes and phobias that minority students hold towards using technology (e.g., Jackson, Ervin, Gardner, \& Schmitt, 2001). We further identified that different enactive and vicarious experiences may shed light on why students develop different attitudes toward STEM fields. For instance, even after gaining access to classroom com- puters, different levels of actual computer usage may still impact students' computer self-efficacy and STEM attitudes. Therefore, both enactive experiences, as well as vicarious experiences, might be key components for improving digital inclusion and reducing digital inequalities moving forward.

Finally, for theoretical implications, there is limited empirical research that focuses on vicarious experience as a source of self-efficacy formation, especially in the context of computing education. This study discloses the mechanisms behind the formation of self-efficacy in the context of a large-scale computing intervention by providing empirical evidence that both enactive as well as vicarious experiences provided sources of technology selfefficacy and STEM attitudes. Furthermore, enactive experience has both direct and indirect effects on student's self-efficacy. For practical implications, school districts seeking to improve digital inclusion should focus on students' enactive experiences, with direct computer usage experiences, in the context of computing or computerbased education, since it is a powerful source of forming self-efficacy. Also, school districts should provide students with more opportunities for vicarious experiences, such as observing teachers' technology usage, since it is a source of STEM attitudes. Future studies should examine the effects of various sources of self-efficacy on the different levels of digital inequality, such as mental access and skills access inequalities, and whether or not these various sources of self-efficacy may have interaction effects on STEM learning.

Over the past several decades we have gained a deep understanding of the kinds of digital inequalities that exist between students; however, we must now look for different kinds of experiences that may increase digital inclusion. The results presented here indicate that enactive and vicarious experiences should be considered during the design of future digital inclusion interventions so that they can become more focused on the experiences associated with the act of computing rather than a sole focus on computers. Advancing digital inclusion will involve more experiential rather than material factors moving forward.

\section{Acknowledgments}

This work was funded by a grant from the National Science Foundation (DRL-1404467; Shelia R. Cotten, PI). The views expressed in this manuscript reflect those of the authors and not the National Science Foundation.

\section{Conflict of Interests}

The authors declare no conflict of interests.

\section{References}

Aesaert, K., \& van Braak, J. (2014). Exploring factors related to primary school pupils' ICT self-efficacy: A 
multilevel approach. Computers in Human Behavior, 41, 327-341. https://doi.org/10.1016/j.chb.2014.10. 006

Araque, J. C., Maiden, R. P., Bravo, N., Estrada, I., Evans, R., Hubchik, K., . . . Reddy, M. (2013). Computer usage and access in low-income urban communities. Computers in Human Behavior, 29(4), 1393-1401.

Ball, C., Huang, K.-T., Cotten, S. R., \& Rikard, R. (2017). Pressurizing the STEM pipeline: An expectancy-value theory analysis of youths' STEM attitudes. Journal of Science Education and Technology, 26(4), 372-382.

Bandura, A. (1977). Self-efficacy: Toward a unifying theory of behavioral change. Psychological Review, $84(2)$.

Bandura, A. (1994). Self-efficacy. In V. S. Ramachaudran (Ed.), Encyclopedia of human behavior (Vol. 4, pp. 71-81). New York, NY: Academic Press.

Bandura, A. (2004). Social cognitive theory for personal and social change by enabling media. In $\mathrm{M}$. J. Cody, E. Rogers, A. Singhal, \& M. Sabido (Eds.), Entertainment-education and social change: History, research, and practice (pp. 75-96). Mahwah, NJ: Lawrence Erlbaum.

Benight, C. C., \& Bandura, A. (2004). Social cognitive theory of posttraumatic recovery: The role of perceived self-efficacy. Behaviour Research and Therapy, 42(10), 1129-1148. https://doi.org/10.1016/ j.brat.2003.08.008

Boz, Y., Yerdelen-Damar, S., Aydemir, N., \& Aydemir, M. (2016). Investigating the relationships among students' self-efficacy beliefs, their perceptions of classroom learning environment, gender, and chemistry achievement through structural equation modeling. Research in Science \& Technological Education, 34(3), 307-324.

DiMaggio, P., Hargittai, E., Celeste, C., \& Shafer, S. (2004). Digital inequality: From unequal access to differentiated use. In Social inequality (pp. 355-400). NewYork, NY: Russell Sage Foundation.

Fieseler, C., Meckel, M., \& Müller, S. (2014). With a little help of my peers. The supportive role of online contacts for the unemployed. Computers in Human Behavior, 41, 164-176.

Hassani, S. N. (2006). Locating digital divides at home, work, and everywhere else. Poetics, 34(4/5), 250-272.

Huang, K.-T., Robinson, L., \& Cotten, S. R. (2015). Mind the emotional gap: The impact of emotional costs on student learning outcomes. In L. Robinson, S. R. Cotton, J. Schulz, T. M. Hale, \& A. Williams (Eds.), Communication and Information Technologies Annual. Digital Distinctions and Inequalities (pp. 121-144). Bingley: Emerald.

Jackson, L. A., Ervin, K. S., Gardner, P. D., \& Schmitt, N. (2001). The racial digital divide: Motivational, affective, and cognitive correlates of internet use 1 . Journal of Applied Social Psychology, 31(10), 2019-2046. Joet, G., Usher, E. L., \& Bressoux, P. (2011). Sources of self-efficacy: An investigation of elementary school students in France. Journal of Educational Psychology, 103(3), 649-663. https://doi.org/10.1037/ a0024048

Kapucu, S., \& Bahçivan, E. (2015). High school students' scientific epistemological beliefs, self-efficacy in learning physics and attitudes toward physics: A structural equation model. Research in Science \& Technological Education, 33(2), 252-267.

Kiran, D., \& Sungur, S. (2012). Sources and consequences of Turkish middle school students' science self-efficacy. Asia-Pacific Education Researcher, 21(1), 172-180.

Melguizo, T., \& Wolniak, G. C. (2012). The earnings benefits of majoring in STEM fields among high achieving minority students. Research in Higher Education, 53(4), 383-405.

National Science Foundation. (2011). Women, minorities, and persons with disabilities in science and engineering: 2011 (NSF 11-309). Alexandria, VA: National Science Foundation. Retrieved from https://www.nsf. gov/statistics/women

Newman, I., \& McNeil, K. (1998). Conducting survey research in the social sciences. New York, NY: University Press of America.

Ng, K. T., Lay, Y. F., Areepattamannil, S., Treagust, D. F., \& Chandrasegaran, A. (2012). Relationship between affect and achievement in science and mathematics in Malaysia and Singapore. Research in Science \& Technological Education, 30(3), 225-237.

Pajares, F., Prestin, A., Chen, J., \& Nabi, R. (2009). Social cognitive theory and mass media effects. In R. L. Nabi \& M. B. oliver (Eds.), The SAGE handbook of media processes and effects (pp. 283-298). London: SAGE.

Paraskeva, F., Bouta, H., \& Papagianni, A. (2008). Individual characteristics and computer self-efficacy in secondary education teachers to integrate technology in educational practice. Computers \& Education, 50(3), 1084-1091. https://doi.org/10.1016/ j.compedu.2006.10.006

Peng, W. (2008). The mediational role of identification in the relationship between experience mode and selfefficacy: Enactive role-playing versus passive observation. CyberPsychology \& Behavior, 11(6), 649-652. https://doi.org/10.1089/cpb.2007.0229

Peng, W. (2009). Design and evaluation of a computer game to promote a healthy diet for young adults. Health Communication, 24(2), 115-127. https://doi. org/10.1080/10410230802676490

Prensky, M. (2001). Digital natives, digital immigrants. On the Horizon, 9(5).

Ritzhaupt, A. D., \& Hohlfeld, T. N. (2018). An examination of the digital divide and its dividing factors in formal educational settings. In A. H. Normore \& A. I. Lahera (Eds), Crossing the bridge of the digital divide: A walk with global leaders (pp. 19-36). Charlotte, NC: Information Age Publishing.

Robinson, L. (2009). A taste for the necessary. Infor- 
mation, Communication \& Society, 12(4), 488-507. https://doi.org/10.1080/13691180902857678

Robinson, L. (2014). Endowed, entrepreneurial, and empowered-strivers: Doing a lot with a lot, doing a lot with a little. Information, Communication \& Society, 17(5), 521-536.

Robinson, L., Cotten, S. R., Ono, H., Quan-Haase, A., Mesch, G., Chen, W., . . . Stern, M. J. (2015). Digital inequalities and why they matter. Information, Communication \& Society, 18(5), 569-582. https:// doi.org/10.1080/1369118X.2015.1012532

Shank, D. B., \& Cotten, S. R. (2014). Does technology empower urban youth? The relationship of technology use to self-efficacy. Computers \& Education, 70, 184-193. https://doi.org/10.1016/j.compedu.2013. 08.018

Usher, E. L. (2009). Sources of middle school students' self-efficacy in mathematics: A qualitative investigation. American Educational Research Journal, 46(1), 275-314. https://doi.org/10.3102/ 0002831208324517

Vandoninck, S., \& Roe, K. (2008). The digital divide in flanders: Disappearance or persistence? Communica- tions, 33(2), 247-255.

van Deursen, A. J. (2015). The third-level digital divide: Who benefits most from Being Online? In J. Helsper Ellen (Ed.), Communication and information technologies annual (Vol. 10, pp. 29-52). Bingley: Emerald.

van Deursen, A. J., \& van Dijk, J. (2013). The digital divide shifts to differences in usage. New Media Society, 16(3), 507-526.

van Dijk, J. (2005). The deepening divide: Inequality in the information society. London: SAGE.

van Dijk, J., \& Hacker, K. (2003). The digital divide as a complex and dynamic phenomenon. The Information Society, 19, 315-326. https://doi.org/10.1080/ 01972240390227895

Wei, K.-K., Teo, H.-H., Chan, H. C., \& Tan, B. (2014). Conceptualizing and testing a social cognitive model of the digital divide. Information Systems Research, 22(1), 170-187.

Zhu, S., Yang, H. H., MacLeod, J., Yu, L., \& Wu, D. (2019). Investigating teenage students' information literacy in China: A social cognitive theory perspective. The Asia-Pacific Education Researcher, 28(3), 251-263.

\section{About the Authors}
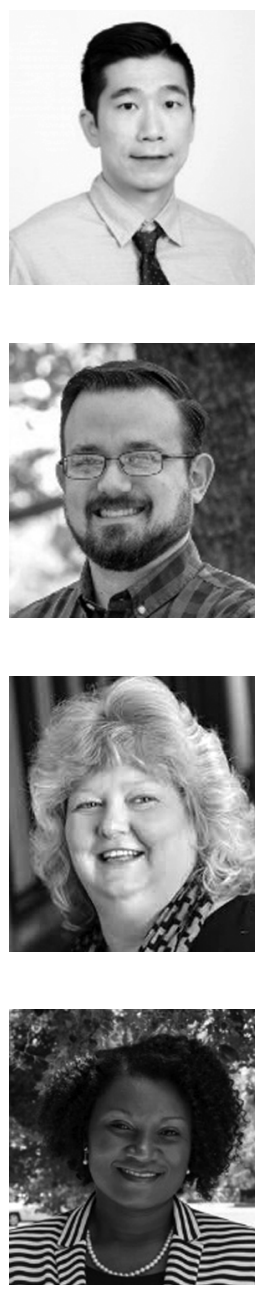

Kuo-Ting Huang (PhD) is an Assistant Professor at Ball State University within the Department of Journalism and the Center for Emerging Media Design and Development. His research focuses on the psychological, cognitive, and affective outcomes of interactive media usage, with an emphasis on digital games and virtual/augmented reality (VR/AR). Specifically, he is interested in how these psychological mechanisms can be harnessed to create virtual reality, augmented reality, and video game experiences that promote educational and health outcomes.

Christopher Ball (PhD) is an Assistant Professor at the University of Illinois at Urbana-Champaign within the Department of Journalism and the Institute of Communications Research. His research interests involve the influence of new technologies on society and how these new technologies can be studied and harnessed for research, education, and outreach purposes. More specifically, his research focuses on the use of interactive media and technologies such as video games, virtual worlds, and virtual reality for pro-social purposes across the life course.

Shelia R. Cotton (PhD) is a Sociologist, an MSU Foundation Professor and Associate Chair for Research at Michigan State University. Beginning August 2020, she will be Associate Vice President for Research Development at Clemson University. Her research examines technology use and impacts across the life course. Her work has been funded by the National Science Foundation, the National Institute on Aging, and the American Center for Mobility, among others. She is currently studying digital overuse across the life course and the workforce impacts of autonomous vehicles.

LaToya O'Neal (PhD) is an Assistant Professor and Extension Health \& Wellness Specialist in the Department of Family, Youth and Community Sciences at the University of Florida. She is a Medical Sociologist who studies the role of the social environment for the health and well-being outcomes of limited resource and African American youth and adults. 